\title{
Lobe-based computed tomography assessment of airway diameter, airway or vessel number, and emphysema extent in relation to the clinical outcomes of COPD
}

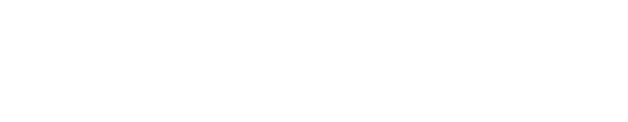

\author{
Kazuyoshi Kurashima' \\ Yotaro Takaku' \\ Toshiko Hoshi ${ }^{2}$ \\ Tetsu Kanauchi² \\ Keitaro Nakamoto' \\ Noboru Takayanagi' \\ Tsutomu Yanagisawa' \\ Yutaka Sugita' \\ Yoshinori Kawabata ${ }^{3}$ \\ 'Respiratory Medicine, ${ }^{2}$ Radiology, \\ ${ }^{3}$ Pathology, Saitama Cardiovascular \\ and Respiratory Center, Saitama, Japan
}

Correspondence: Kazuyoshi Kurashima Department of Respiratory Medicine, Saitama Cardiovascular and Respiratory Center, Itai I696, Kumagaya City,

Saitama, Japan

$\mathrm{Tel}+8 \mid 492238638$

Fax +8I 492238638

Email kurashima.kazuyoshi@pref.saitama. Ig.jp
Objective: The aim of this study was to evaluate the relationship between computed tomography assessed lobe-based lung parameters and the clinical outcomes of patients with chronic obstructive pulmonary disease (COPD), including the frequency of exacerbation and annual change in forced expiratory volume in 1 second $\left(\mathrm{FEV}_{1}\right)$.

Patients and methods: We studied 65 patients with COPD. We reconstructed computed tomography images to trace the bronchial tree from right $\mathrm{B} 1$ to $\mathrm{B} 10$ and created $3 \mathrm{~cm}$ circle images around the airways exactly perpendicular to the airway axis in the central, middle, and peripheral zones of the bronchi. The number of airways and vessels, airway inner diameter and area of emphysema in the circles were calculated for each segment. Then, we analyzed the relationships between the lobe-based image parameters and the frequency of exacerbation and annual decline in the $\mathrm{FEV}_{1}$. In addition, we assessed the effects of proximal airway lumenobliterated emphysema (ALOE) on these clinical features.

Results: The airway diameter was not associated with the frequency of exacerbation or annual decline in $\mathrm{FEV}_{1}$. Among the structural parameters, lower lobe emphysema was most associated with the frequency of exacerbation. The reductions in the number of airways and vessels in total lobe were associated with the annual decline in $\mathrm{FEV}_{1}$. The subgroup of patients with ALOE demonstrated lower $\mathrm{FEV}_{1}$ and more frequent exacerbation than those without ALOE.

Conclusion: Lower lobe emphysema predicts frequent COPD exacerbation, whereas the annual decline in $\mathrm{FEV}_{1}$ is associated with the number of airways and vessels in total lobe.

Keywords: chronic obstructive pulmonary disease, computed tomography, acute exacerbation, pulmonary function tests, low attenuation area

\section{Introduction}

The clinical course of chronic obstructive pulmonary disease (COPD) is considerably heterogeneous, with a portion of patients experiencing frequent exacerbation and a rapid decline in the forced expiratory volume in 1 second $\left(\mathrm{FEV}_{1}\right) .{ }^{1,2}$ Acute exacerbation accelerates the decline in the lung function and is associated with an impaired quality of life and higher mortality. ${ }^{3-6}$ Therefore, the frequency of exacerbation and annual decline in $\mathrm{FEV}_{1}$ are key parameters for COPD treatment. The ability to predict which patients are at greater risk of exacerbation and rapid decline in $\mathrm{FEV}_{1}$ would be beneficial for targeting these patients for the early introduction of preventive therapy.

Following advances in computed tomography (CT), it is becoming an important tool for evaluating COPD. Quantitative CT measurements of the degree of emphysema and 
the airway wall thickness have been explored to identify subgroups of patients with COPD who experience more frequent exacerbation. ${ }^{7}$ However, more detailed lung parameters of the upper, lower, and/or total lobes have not been previously evaluated in relation to the clinical outcomes of COPD. In a previous study, we evaluated the airway diameter and lung parameters in $3 \mathrm{~cm}$ circles along the airways in the right B1 to B10 bronchi from the level of the segmental bronchi to the peripheral airways $2 \mathrm{~cm}$ from the pleura by CT using curved multi-planar reconstruction (MPR) of the airways with an ultra-high resolution (UHR) mode and an interactive reconstruction algorithm. ${ }^{8}$ These segment-based analyses of lung parameters enabled us to study the relationship between lobe-based lung parameters and longitudinal clinical outcomes of COPD. In a previous study, we observed significant association of lower lobe emphysema with the progression of airflow limitation stage. ${ }^{8}$ In addition, by tracing the airways, we previously identified a distinctive type of emphysema, airway lumen-obliterated emphysema (ALOE), with complete luminal occlusion of the proximal conducting airway accompanied by sub-segmental confluent emphysema separated by clear border from the surrounding segments. ${ }^{8}$ The obliterated airway could be traced into the extensively destructed area. In contrast to the confluent centrilobular emphysema, this type of emphysema was typically observed in lower lobes.

Based on these previous observations, we studied to examine whether lobe-based lung parameters, such as the airway diameter, percentage of low attenuation areas (\%LAA), and number of airways and vessels are associated with the frequency of exacerbation and annual decline in $\mathrm{FEV}_{1}$ in patients with COPD. Second, we stratified COPD patients with and without ALOE and compared the above clinical features between the two groups.

\section{Methods}

\section{Patients}

We previously studied 70 Japanese males with COPD who underwent UHR-CT for an evaluation of emphysema between March 1 and October 31, 2012. ${ }^{8}$ We checked medical records and inquired about episodes of exacerbation during the previous 1 year prior to that study until October 31, 2014. Among the 70 subjects, we studied 65 patients who had records of at least two sets of pulmonary function tests (PFTs) performed 1 year after the first PFT. If PFTs were recorded for more than 2 years, the mean annual change in $\mathrm{FEV}_{1}$ was calculated. Subjects exhibiting a history of allergies, episodic wheezing, or a high serum IgE level were excluded. Patients were treated and cared for according to the Japanese guidelines of COPD. ${ }^{9}$ Patients were all ex-smokers at the start of this study. Exacerbation was defined as the number of respiratory exacerbations requiring treatment with antibiotics and/ or steroids. We recorded number of level I exacerbations: treated at home; and number of level II/III exacerbations: requiring hospitalization or leading to respiratory failure. ${ }^{10}$ The institutional Review Board of Saitama Cardiovascular and Respiratory Center approved this study (IRB No 2011002), and all subjects provided their written informed consent prior to participation in the study.

\section{PFTs}

The PFTs were performed using a CHESTAC8800 device (Chest MI Corp., Tokyo, Japan). PFT data included measurements of forced vital capacity and $\mathrm{FEV}_{1}$. The methods for obtaining the spirometric measurements and their predicted values were derived from the guidelines for PFTs issued by the American Thoracic Society/European Respiratory Society and Japanese Respiratory Society. ${ }^{11,12}$ Spirometry was performed before and 30 minutes after the inhalation of $200 \mu \mathrm{g}$ of salbutamol, and the data obtained after salbutamol inhalation were used for the evaluation.

Spirometry was to be done at the start of the study and every year during the study.

\section{CT data acquisition and reconstruction}

We used the image data of 65 subjects assessed in our previous study. ${ }^{8}$ In brief, a multi-slice CT scanner (256 slices, Brilliance iCT; Philips Healthcare, Cleveland, OH, USA) was used. The CT scans were acquired with the following parameters: tube voltage: $120 \mathrm{kVp}$; tube current-time product: $200 \mathrm{mAs}$; detector configuration: $20 \times 0.625 \mathrm{~mm}$ collimation with UHR mode; reconstruction section thickness; $0.67 \mathrm{~mm}$, helical mode with 0.55 pitch; gantry rotation time: 0.4 seconds; display field of view: $200 \mathrm{~mm}$. In order to reduce image noise, all images were reconstructed from UHR data using an interactive reconstruction algorithm (iDose ${ }^{4}$; Philips Healthcare). ${ }^{13-15}$ The patients were asked to inhale deeply and hold for several moments, after which the scans were obtained. The reconstructed data were transferred to a workstation (Brilliance ${ }^{\mathrm{TM}}$ Workspace Portal; Philips Healthcare) and then reconstructed into the curved MPR of the airway.

\section{Analysis of the airway structures}

We calculated CT image parameters obtained in our previous study $^{8}$ for the total lobe (B1-B10), upper lobe (B1-B3) and lower lobe (B6-B10). In brief, we previously obtained the 
7,800 data sets (inner diameter, airway and vessel number, and \%LAA) from 1,950 circle images (30 points in 10 right bronchial trees) in 65 COPD patients in a partially different manner from that applied in our previous study, ${ }^{8}$ ie, they were calculated for each lobe. In brief, the right B1 to B10 bronchial trees were analyzed. The bronchial tree was traced from the peripheral point of the airway within $2 \mathrm{~cm}$ from the pleura to the entrance of the segmental bronchus. We designated the point in the airway $2 \mathrm{~cm}$ from the pleura as the peripheral zone, the point $2 \mathrm{~cm}$ from the entrance of the segmental bronchus as the central zone, and the point halfway between these two points as the middle zone. At each point, we reconstructed images perpendicular to the axis of the airway and set a $3 \mathrm{~cm}$ circle with the selected airway in the center. Using a method previously reported with minor modifications, \%LAA was calculated in the circle. ${ }^{16-18}$ The number of airways as well as arteries and veins (vessels) in the circle and the inner diameter of the airway at the center of the circle was measured.

\section{ALOE and clinical outcomes}

ALOE is characterized by proximal airway lumen occlusion and sub-segmental air-trapped emphysema. ${ }^{8}$ Since it can be recognized as an extensively destructed area clearly separated from next segments, the numbers of segments with ALOE were counted and their relationships to the $\% \mathrm{FEV}_{1}$, annual change of $\mathrm{FEV}_{1}$, and frequency of exacerbation were analyzed.

\section{Statistical analysis}

The statistical analyses were performed using Prism 5 software program (GraphPad Software, Inc., La Jolla, CA, USA), and the data are expressed as the mean \pm standard deviation. Spearman's rank test was used to assess the correlations between the imaging data and the clinical parameters including the frequency of exacerbation and annual decline in $\mathrm{FEV}_{1}$. The Mann-Whitney $U$-test was used to compare parameters between the subjects with and without ALOE. A $P$-value of less than 0.05 was considered to be statistically significant.

\section{Results \\ Clinical characteristics}

The subjects' demographics are presented in Table 1. These data are stratified by the presence of ALOE. Of the total 65 subjects, $26(40 \%)$ subjects had ALOE in one or more bronchi. There were no differences in age, the smokingindex, annual change in $\mathrm{FEV}_{1}$ or airway reversibility between the groups with and without ALOE. However, the subjects with ALOE had lower body mass index $\left(18.9 \pm 3.1 \mathrm{~kg} / \mathrm{m}^{2}\right.$ versus (vs) $21.5 \pm 3.5 \mathrm{~kg} / \mathrm{m}^{2}, P=0.006$ ), forced vital capacity (75.4 \pm 14.1 vs $89.2 \pm 23.1$, \% predicted, $P=0.009$ ) and $\mathrm{FEV}_{1}$ (43.4 \pm 18.3 vs $76.0 \pm 30.6$, \% predicted, $P<0.001)$ values than the subjects without ALOE. Inhaled corticosteroids were used in $50.8 \%$ of total patients, and the patients with ALOE used more inhaled corticosteroids and long-acting muscarinic antagonists than those without ALOE. At the

Table I Demographic data of the subjects stratified for presence of airway-lumen obliterated emphysema

\begin{tabular}{|c|c|c|c|c|}
\hline & Total & ALOE, yes & ALOE, no & $P$ \\
\hline Number & 65 & 26 & 39 & \\
\hline Age & $70.8(6.4)$ & $70.5(5.9)$ & $71.0(6.9)$ & NS \\
\hline Pack-years & $76.2(34.7)$ & $76.1(33.0)$ & $76.3(36.3)$ & NS \\
\hline Body mass index & $20.5(3.6)$ & $18.9(3.1)$ & $21.5(3.5)$ & $P=0.006$ \\
\hline FVC, \% predicted & $83.7(21.0)$ & $75.4(14.1)$ & $89.3(23.1)$ & $P=0.009$ \\
\hline $\mathrm{FEV}_{1}, \%$ predicted & $62.9(30.7)$ & $43.4(18.3)$ & $76.0(30.6)$ & $P<0.001$ \\
\hline $\mathrm{FEV}_{1}$, change, $\mathrm{mL} / \mathrm{yr}$ & $-34.3(38.7)$ & $-32.0(36.6)$ & $-35.7(40.5)$ & NS \\
\hline $\mathrm{FEV}_{1}$, reversibility, \% & $4.9(7.3)$ & $5.8(7.0)$ & $4.4(7.6)$ & NS \\
\hline \multicolumn{5}{|l|}{ Treatments } \\
\hline Inhaled corticosteroids & $50.8 \%$ & $69.2 \%$ & $38.5 \%$ & $P=0.023$ \\
\hline Long-acting $\beta$-agonist & $56.9 \%$ & $73.1 \%$ & $48.7 \%$ & NS \\
\hline Long-acting muscarinic antagonists & $73.8 \%$ & $84.6 \%$ & $66.7 \%$ & $P=0.018$ \\
\hline \multicolumn{5}{|l|}{ Treatments for exacerbations } \\
\hline Antibiotics & $100 \%$ & $100 \%$ & $100 \%$ & NS \\
\hline Systemic & $20.8 \%$ & $29.2 \%$ & $12.5 \%$ & NS \\
\hline Corticosteroids & & & & \\
\hline
\end{tabular}

Notes: $P$, significance of difference between groups with or without ALOE was analyzed by Mann-Whitney $U$-test. Means (standard deviation) are expressed for number, age, body mass index, FVC, FEV , changes of FEV , and reversibility of FEV . Percentages of the drugs used are expressed for the daily treatments and treatments for exacerbations.

Abbreviations: ALOE, airway lumen-obliterated emphysema; FVC, forced expiratory volume; FEV , forced expiratory volume in I second; yr, year; NS, not significant. 
time of COPD exacerbation, systemic corticosteroids were used in $20.8 \%$ of cases.

\section{Lung parameters and frequency of COPD exacerbation}

The mean overall exacerbation frequency was $0.67 \pm 0.85$ exacerbations per year and exacerbation that needed hospitalization was $0.21 \pm 0.37$ per year. There were no correlations between the post-bronchodilator airway diameter or number of airways/vessels and the frequency of exacerbation. However, the \%LAA of the total lobe correlated with the frequency of exacerbation $(r=0.452, P<0.001)$, with the lower-lobe \%LAA being most correlated with the incidence of exacerbation ( $r=0.499, P<0.001)$ (Figure 1$)$.

\section{Lung structures and annual change in FEV,} There were no correlations between the post-bronchodilator airway diameter or \%LAA and the annual change in $\mathrm{FEV}_{1}$. However, the mean numbers of airways and vessels in the circles of total lobe, but not upper or lower lobes, weakly correlated with the annual change in $\mathrm{FEV}_{1}(r=0.259, P=0.047$ and $r=0.293, P=0.024$, respectively). The heterogeneity in the number of airways and vessels was observed by curved MPR images of airways. Figure 2 shows two representative phenotypes of COPD with less preserved (Figure 2A) or more preserved (Figure 2B) airway/vessel structures along the airways. To show heterogeneity in the number of airways/vessels in relation to extent of emphysema, we plotted mean numbers of airway/vessel to the mean \%LAA in $3 \mathrm{~cm}$ circles in total lobe (Figure 3). The figure shows that correlations between number of airways/vessels and \%LAA were weak ( $r=-0.276, P=0.026$; $r=-0.369, P=0.002$, respectively), and there were significant heterogeneities in the amount of airways and vessels to the extent of emphysema. We stratified the subgroups of patients who had more preserved airways/vessels above or on the line of linear regression lines and less preserved groups of patients whose plots were under the lines. The subgroup of patients who had more preserved vessels along airways (Figure $3 \mathrm{Ab}$, $\mathrm{n}=29$ ) had smaller decline of $\mathrm{FEV}_{1}$ compared to those (Figure 3Aa, $\mathrm{n}=36)$ with less preserved vessels $(-21.7 \pm 33.1 \mathrm{~mL} / \mathrm{yr}$ vs $-43.8 \pm 32.5 \mathrm{~mL} / \mathrm{yr}$, respectively, $P=0.015)$. The annual declines of $\mathrm{FEV}_{1}$ in patients with more or less preserved airways were $-26.4 \pm 44.7 \mathrm{~mL} / \mathrm{yr}$ (Figure $3 \mathrm{Bb}, \mathrm{n}=29) \mathrm{vs}-40.6 \pm 32.5 \mathrm{~mL} / \mathrm{yr}$ (Figure $3 \mathrm{Ba}, \mathrm{n}=36)$, respectively $(P=0.062)$.

\section{Clinical features of ALOE}

The curved MPR images of airways showed a distinctive type of emphysema; ALOE. ${ }^{8}$ ALOE was observed in 60 segments of 26 patients (eight in upper lobe, 19 in middle lobe, and 33 in lower lobe). Of note, 14 (23.3\%) cases of ALOE were observed in B7. The patients with ALOE had lower post-bronchodilator $\% \mathrm{FEV}_{1}$ than those without $\mathrm{ALOE}$ $(48.5 \% \pm 21.2 \%$ vs $76.0 \% \pm 30.6 \%, P<0.001$, Figure $4 \mathrm{~A})$. However, the presence of ALOE had no correlation to the annual decline in $\mathrm{FEV}_{1}$ (Figure 4B). The subjects with ALOE demonstrated a greater frequency of exacerbation than the COPD subjects without ALOE (1.05 \pm 1.12 per year vs $0.42 \pm 0.48$ per year, respectively, $P<0.001$ ) (Figure 5).

\section{Discussion}

In the present study, the frequency of COPD exacerbation was most associated with lower lobe emphysema, whereas the annual decline in $\mathrm{FEV}_{1}$ was associated with the numbers of airways and vessels. The patients with ALOE exhibited severe airflow limitations and more frequent episodes of exacerbation than the patients without ALOE. These data suggest that specific CT-assessed lung structures are associated with specific longitudinal outcomes of COPD.
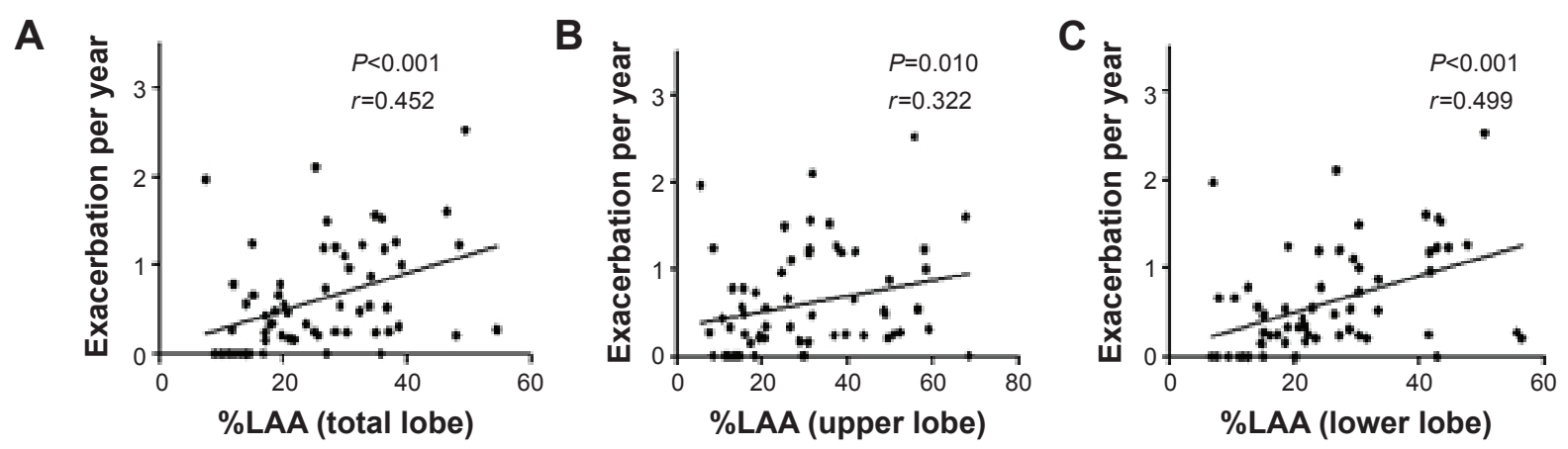

Figure I Percentages of low attenuation area (\%LAA) and frequency of COPD exacerbation.

Notes: Panels (A-C) demonstrate the relationship between frequency of COPD exacerbation and \%LAA in total lobe (right BI-BI0, [A]), upper lobe (right BI-B3, [B]) and lower lobe (right B6-BI0, [C]). Each \%LAA value shows mean value of $3 \mathrm{~cm}$ circle images exactly perpendicular to the axis of the airways at central zone (2 cm from the entrance of segmental bronchus), peripheral zone ( $2 \mathrm{~cm}$ from the pleura), and middle zone (halfway point of central and peripheral points) of each bronchus. Abbreviation: COPD, chronic obstructive pulmonary disease. 


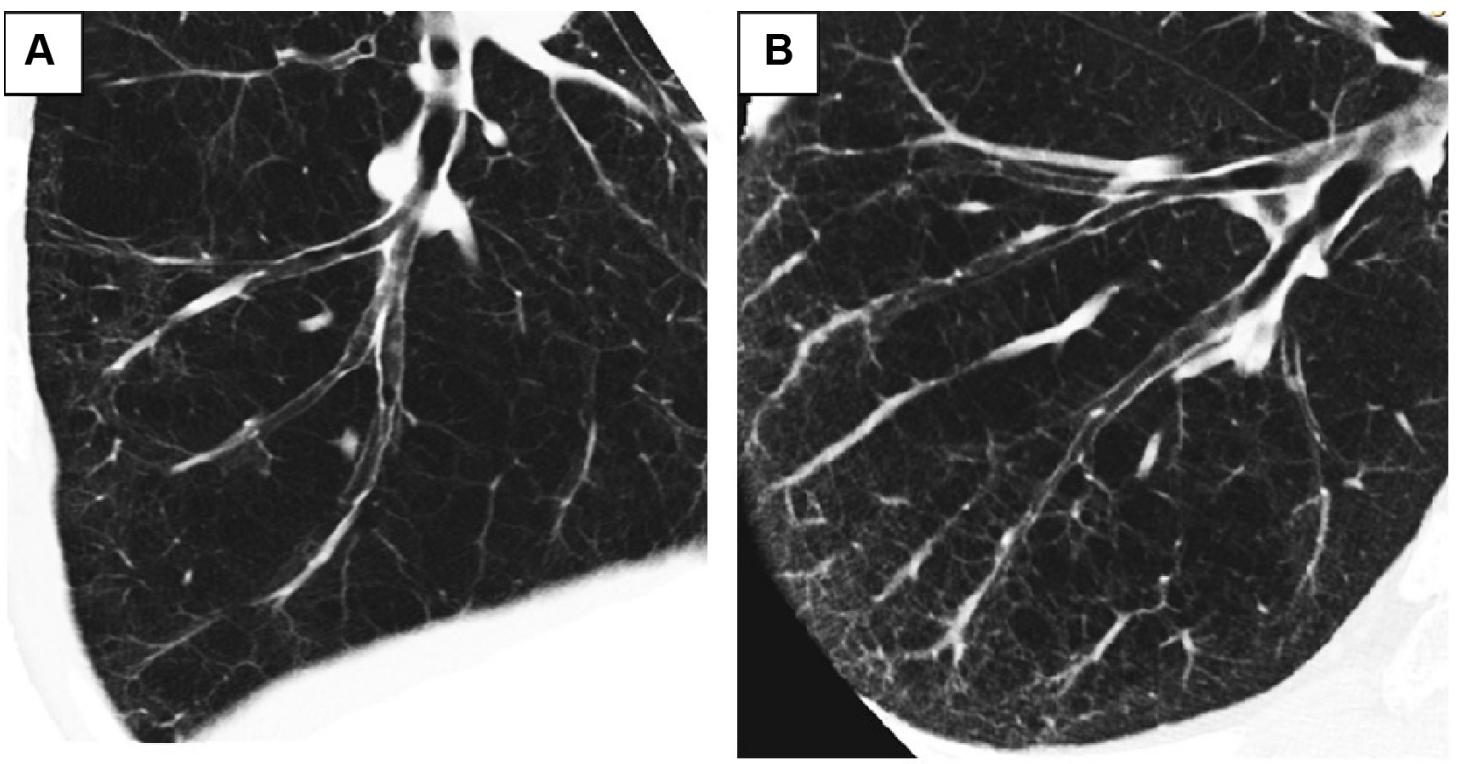

Figure 2 Two phenotypes of emphysema in relation to the numbers of airways and vessels.

Notes: Two phenotypes of emphysema are shown. Right B9 bronchi were traced from entrance of segmental bronchi to the peripheral bronchi by curved multi-planar reconstruction images. Both cases had a similar percentage predicted diffusion capacity to carbon monoxide (\%DLco: $56.5 \%$ versus $53.0 \%$, respectively), but patient (A) has fewer lung structures around airways and patient (B) has more lung structures around airways. Case (A) had a lower \%FEV, value (62.9\% versus $129.0 \%$, respectively) and demonstrated a rapid annual decline in $\mathrm{FEV}_{1}(-104 \mathrm{~mL}$ per year versus $-55 \mathrm{~mL}$ per year, respectively) compared to case (B).

Abbreviation: $\mathrm{FEV}_{1}$, forced expiratory volume in I second.

In a previous study, we reported that the post-bronchodilator $\% \mathrm{FEV}_{1}$ was most associated with the mean airway diameter and partially associated with the middle zone \%LAA and the number of peripheral zone airways. ${ }^{8}$ In the current study, the airway diameter was not associated with the frequency of COPD exacerbation or the annual change in $\mathrm{FEV}_{1}$. These data may partially explain why COPD stage which is defined by $\% \mathrm{FEV}_{1}$ is not well associated with the frequency of exacerbation. ${ }^{1}$

In contrast, this study showed that emphysema was associated with the frequency of exacerbation. The result is in accordance with previous observations in the COPDGene study that demonstrated emphysema and airway wall thickness to be risk factors for COPD exacerbation. ${ }^{7}$ Compared to that study,
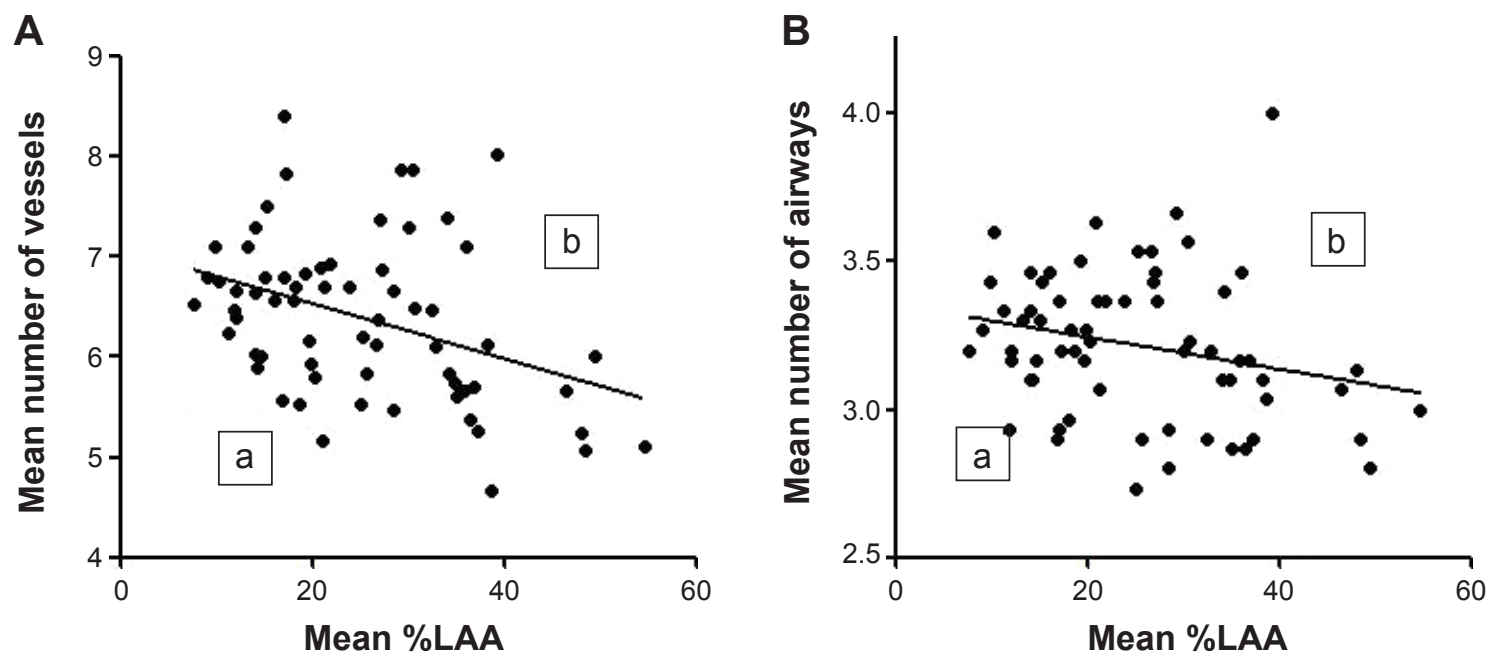

Figure 3 The numbers of airways and vessels and the extent of emphysema.

Notes: The mean numbers of vessels (A) and airways $(\mathbf{B})$ in $3 \mathrm{~cm}$ circles along right BI to BI0 airways were plotted to the mean percentage of low attenuation areas (\%LAA). Segments (a) are under and (b) are above/on the linear regression lines. The subgroup of patients in $(\mathbf{A a})(\mathrm{n}=36)$ who had less vessels along airways had larger annual decline of $\mathrm{FEV}_{1}(-43.8 \mathrm{~mL}$ per year) compared to that of $(\mathbf{A b})(\mathrm{n}=29)(-21.7 \mathrm{~mL}$ per year; $P=0.015)$. The annual declines of $F E V$ in patients $(\mathrm{a})$ and $(\mathrm{b})$ in $(\mathbf{B}) \mathrm{were}-40.6 \mathrm{~mL}$ per year $(n=36)$ versus $-26.4 \mathrm{~mL}$ per year $(n=29)$, respectively $(P=0.062)$.

Abbreviation: $\mathrm{FEV}_{1}$, forced expiratory volume in I second. 

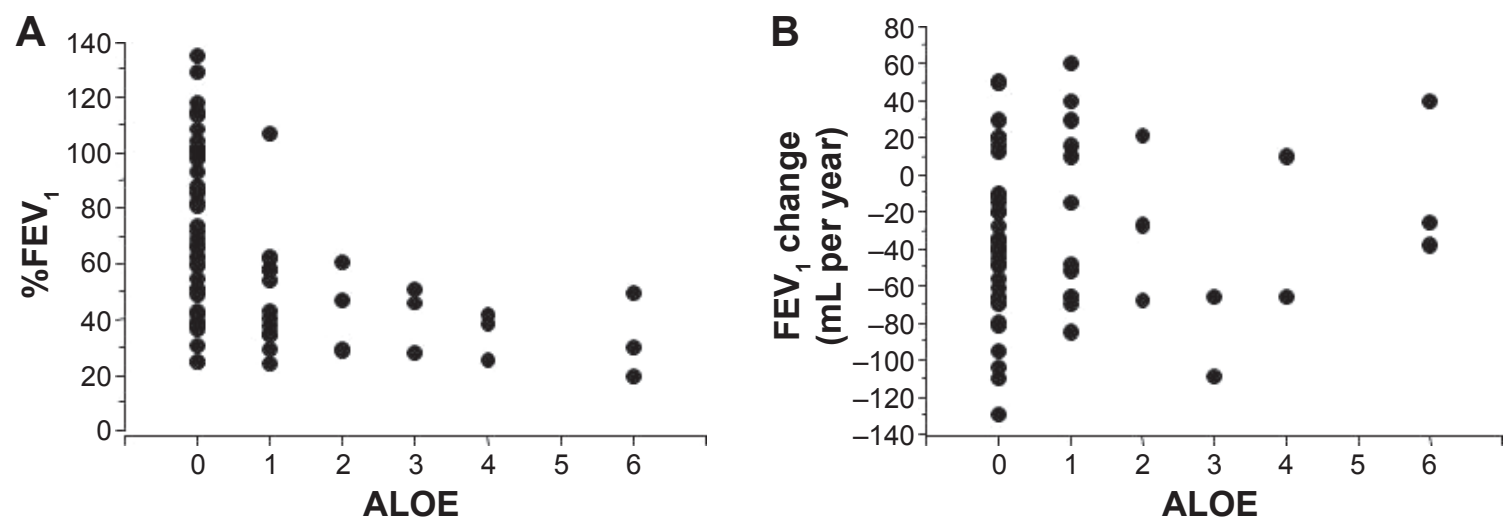

Figure 4 Numbers of airway lumen-obliterated emphysema (ALOE) and \%FEV, and annual change in FEV . Notes: (A) Shows numbers of ALOE observed in right lung and predicted \%FEV . (B) Shows numbers of ALOE observed in right lung and annual changes in FEV . Abbreviation: $\mathrm{FEV}_{1}$, forced expiratory volume in I second.

the present study included a small sample size and did not analyze airway wall thickness. However, we further revealed that lower lobe emphysema was more important compared to the other lung structures. One of the potential explanations for the association between frequency of exacerbation and lower lobe emphysema is the difficulty in airway clearance in the lower lobe. The airways are supplied with alveolar surfactant ${ }^{19}$ and surfactant is thought to be important for small airway potency ${ }^{20}$ and mucociliary clearance. ${ }^{21,22}$ The reduced supply of surfactant and the reduced exhaled airflow resulting from upstream emphysema makes sputum clearance more difficult in the lower lobe vs the upper lobe.

Previous reports showed that emphysema is associated with rapid decline in $\mathrm{FEV}_{1} \cdot{ }^{23,24}$ We further demonstrated in this study that reduced numbers of airways/vessels along the airways rather than emphysema itself were associated

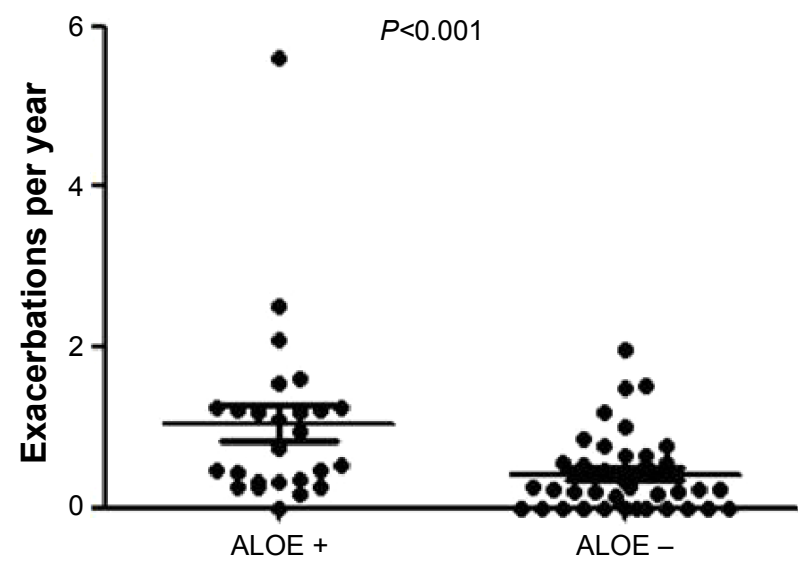

Figure 5 Frequency of COPD exacerbation and presence of airway lumen-obliterated emphysema (ALOE).

Notes: Frequencies of COPD exacerbation are compared in patients with or without ALOE. Horizontal bars represent mean values.

Abbreviation: COPD, chronic obstructive pulmonary disease. with annual decline of $\mathrm{FEV}_{1}$. Emphysema is preceded by the reduction of airways, ${ }^{25}$ but we found heterogeneity in the numbers of airways/vessels to the extent of emphysema. Airways and vessels are connected by "septal fibers" as reported by Weibel, ${ }^{26}$ and we clearly demonstrated interstitial connections among airways and vessels in our previous study. ${ }^{8}$ One potential explanation for the results of this study is that subjects with preserved airways/vessels might be more resistant to the mechanical stress from repeated air trapping.

Finally, the presence of ALOE was associated with severe airflow limitation and the frequency of exacerbation. It is possible that sub-segmental air trapping in the lower lobe interferes with the movement of the diaphragm. However, further studies are needed about the nature and clinical significance of ALOE.

There are several limitations associated with this study that should be noted. The number of subjects was limited, such that some of the parameters may have been found to be significant in a much larger study. However, we believe that the current study successfully demonstrated the relative significance of the lung parameters. The results of the present study do not necessarily contradict the reported effects of long-acting bronchodilators in preventing COPD exacerbation, ${ }^{24,27}$ because we examined the airway diameter after the use of a short-acting bronchodilator, and did not assess the effects of full-day airway potency. In addition, the effects of daily treatments cannot be assessed because of the observational study design.

In conclusion, in spite of several limitations, lobe-based $\mathrm{CT}$ assessment of airways and lung structures along the airway can provide useful information about lung function and clinical outcomes of COPD. Presence of lower lobe 
emphysema and ALOE can be used to define subgroups of COPD patients who experience more exacerbations. These patients need special health care because sputum clearance is much more difficult in lower lobes than in upper lobes. In addition, reduction of airways/vessels occurs in the very early stages of COPD ${ }^{8}$ recognizing these changes at an early stage is important for improving the clinical outcome.

\section{Disclosure}

The authors have no conflict of interest to disclose.

\section{References}

1. Hurst JR, Vestobo J, Anzueto A, et al. Susceptibility to exacerbation in chronic obstructive pulmonary disease. $N$ Engl J Med. 2010; 363(12):1128-1138.

2. Vestobo J, Edwards LD, Scanlon PD, et al. Changes in forced expiratory volume in 1 second over time in COPD. N Engl J Med. 2011;365(13): 1184-1192.

3. Donaldson GC, Seemungal TA, Bhowmik A, Wedzicha JA. Relationship between exacerbation frequency and lung function decline in chronic obstructive pulmonary disease. Thorax. 2002;57(10):847-852.

4. Donaldson GC, Wilkinson TM, Hurst JR, et al. Exacerbations and time spent outdoors in chronic obstructive pulmonary disease. Am J Respir Crit Care Med. 2005;171(5):446-452.

5. Seemungal TA, Donaldson GC, Paul EA, et al. Effect of exacerbation on quality of life in patients with chronic obstructive pulmonary disease. Am J Respir Crit Care Med. 1998;157(5 Pt 1):1418-1422.

6. Soler-Cataluna JJ, Martinez-Garcia MA, Roman Sanchez P, et al. Severe acute exacerbations and mortality in patients with chronic obstructive pulmonary disease. Thorax. 2005;60(11):925-931.

7. Han MK, Kazerooni EA, Lynch DA, et al. Chronic obstructive pulmonary disease exacerbations in the COPDGene study: Associated radiologic phenotypes. Radiology. 2011;261(1):274-282.

8. Kurashima K, Hoshi T, Takaku Y, et al. Changes in the airway lumen and surrounding parenchyma in chronic obstructive pulmonary disease. Int J Chron Obstruct Pulmon Dis. 2013;8:523-532.

9. Japanese Respiratory Society. [Guideline for diagnosis and management of COPD (chronic obstructive pulmonary disease). The Third Edition: therapy and management]. Nihon Kokyuki Gakkai Zasshi. 2009;Suppl Copd:70-144. Japanese.

10. Celli BR, MacNee W; ATS/ERS Task Force. Standards for the diagnosis and treatment of patients with COPD: a summary of the ATS/ ERS position paper. Eur Respir J. 2004;23(6):932-946.

11. Miller MR, Hankinson J, Brusasco V, et al. Standardisation of spirometry. Eur Respir J. 2005;26(2):319-338.
12. Japanese Respiratory Society. [The predicted values of spirometry and arterial blood gas analysis in Japanese]. J Jpn Resp Soc. 2001;39: Appendix. Japanese.

13. Noël PB, Fingerle AA, Renger B, et al. Initial performance characterization of a noise-suppressing reconstruction algorithm for MDCT. AJR Am J Roentgenol. 2011;197(6):1404-1409.

14. Miéville FA, Gudinchet F, Brunelle F, Bochud FO, Verdun FR. Iterative reconstruction methods in two different MDCT scanners: Physical metrics and 4-alternative forced-choice detectability experiments - a phantom approach. Phys Med. 2013;29(1):99-100.

15. Rajiah $P$, Schoenhagen $P$, Mehta $D$, et al. Low-dose, wide-detector array thoracic $\mathrm{CT}$ angiography using an iterative reconstruction technique results in improved image quality with lower noise and fewer artifacts. J Cardiovasc Comput Tomogr. 2012;6(3):205-213.

16. Sakai N, Mishima M, Nishimura K, Itoh H, Kuno K. An automated method to assess the distribution of low attenuation areas on chest CT scans in chronic pulmonary emphysema patients. Chest. 1994;106(5): 1319-1325.

17. Nakano Y, Sakai H, Muro S, et al. Comparison of low attenuation areas on CT between inner and outer segments of the lung in COPD patients: incidence and contribution to lung function. Thorax. 1999;54(5):384-389.

18. Mishima M, Oku Y, Kawakami K, et al. Quantitative assessment of the spatial distribution of low attenuation areas on X-ray CT using texture analysis in patients with chronic pulmonary emphysema. Front Med Biol Eng. 1997;8(1):19-34.

19. Pettenazzo A, Jobe A, Humme J, Seidner S, Ikegami M. Clearance of surfactant phosphatidylcholine via the upper airways in rabbits. $J$ Appl Phjysiol (1988). 1988;65(5):2151-2155.

20. Macklem PT. Airway obstruction and collateral ventilation. Physiol Rev. 1971;51(2):368-436.

21. Rensch H, von Seefeld H. Surfactant-mucus interaction. In: Robertson B, van Golde LM, Batenburg JJ, editors. Pulmonary Surfactant. Elsevier; 1984:203.

22. Morgenroth $\mathrm{K}$. Morphology of bronchial lining layer and its alternation in IRDS, ARDS and COLD. Eur J Respir Dis Suppl. 1985;142:7-18.

23. Nishimura M, Makita H, Nagai K, et al. Annual change in pulmonary function and clinical phenotype in chronic obstructive pulmonary disease. Am J Respir Crit Care Med. 2012;185(1):44-52.

24. Tashkin DP, Celli B, Senn S, et al. A four-year trial of tiotropium in chronic obstructive pulmonary disease. $N$ Engl J Med. 2008;359(15): $1543-1554$.

25. McDonough JE, Yuan R, Suzuki M, et al. Small-airway obstruction and emphysema in chronic obstructive pulmonary disease. $N$ Engl J Med. 2011;365(17):1567-1575.

26. Weibel ER. It takes more than cells to make a good lung. Am J Respir Crit Care Med. 2013;187(4):342-346.

27. Calverley PM, Anderson JA, Celli B, et al. Salmeterol and fluticasone propionate and survival in chronic obstructive pulmonary disease. N Engl J Med. 2007;356(8):775-789.
International Journal of COPD

\section{Publish your work in this journal}

The International Journal of COPD is an international, peer-reviewed journal of therapeutics and pharmacology focusing on concise rapid reporting of clinical studies and reviews in COPD. Special focus is given to the pathophysiological processes underlying the disease, intervention programs, patient focused education, and self management protocols.

\section{Dovepress}

This journal is indexed on PubMed Central, MedLine and CAS. The manuscript management system is completely online and includes a very quick and fair peer-review system, which is all easy to use. Visit http://www.dovepress.com/testimonials.php to read real quotes from published authors. 